\title{
LA HOMOLOGÍA ESTRUCTURAL EN LAS ADAPTACIONES CINEMATOGRÁFICAS
}

\author{
José García Templado
}

Universidad Complutense de Madrid

0. El análisis de las adaptaciones cinematográficas de obras narrativas y su contraste con las obras originales puede verse favorecido por el uso del ordenador. Las tarjetas multimedia, capaces de descomponer y combinar en su soporte electrónico texto, imagen y sonido, permiten fragmentar las obras en secuencias que hagan coincidir original y adaptación. Los fallos de memoria, que el visionado completo de un film plantea en una clase, quedan así salvados.

El análisis de los correspondientes segmentos pondrá de manifiesto los vínculos, diferencias y matices de los procesos de creación, y podrá determinar la homologación de las partes y su repercusión en el componente semántico. Las variaciones de la traducción intersemiótica responde a las posibilidades de los lenguajes específicos, cuyas retóricas se ven libres de correspondencia estricta, gracias al fenómeno que conocemos como homología estructural. 


\section{LOS CONCEPTOS}

1.1. A pesar de la complejidad de las estructuras semióticas que intervienen en la comunicación, es posible encontrar alguna equivalencia entre sus formas, de modo que puedan intercambiarse. Para que esto ocurra, debe existir una homologación entre dichas formas, de manera que la libertad de selección de uno u otro repertorio dé al autor posibilidades creativas sin que se altere el sentido fundamental de la obra.

Hablamos de homologación como la «operación de análisis semántico que afecta a todos los dominios semióticos y que participa del procedimiento general de la estructuración» (Greimas y Courtès, 1990: 90), entendiendo la obra como una superestructura.

Sabemos que la estructura lingüística forma parte esencial de cualquier hecho de comunicación, en nuestro ámbito, en el que intervienen otras estructuras. Se encuentra, con respecto a éstas, en una relación estructural de recambio, redundancia, contradicción, complementariedad, divergencia o neutralización. Añado divergencia y neutralización a las relaciones señaladas por Barthes, puesto que puede que las palabras nada tengan que ver con las intenciones significativas que los rasgos suprasegmentales y el resto de las estructuras semióticas que las acompañan dan a las frases pronunciadas. Es decir, forman parte de un hipertexto que, simultáneamente, alude a referentes distintos.

En la pieza de teatro colectivo con la que se dio a conocer el grupo Tábano, titulada El juego de los dominantes, un personaje era torturado por los otros arrojándole a los oídos los títulos de las obras de José María Pemán, mientras que el torturado pedía clemencia y se justificaba recitando la biografía del autor gaditano, tal y como viene en la enciclopedia Espasa (Grupo Tábano, 1971: 17; Margallo, 1975: 32).

Las estructuras kinésica y proxémica, donde se materializan las actitudes y gestos de súplica y dominancia, no pretenden neutralizar, contradecir o subsumir las palabras, sino que las mantienen con un valor irónico y crítico que se corresponde con el momento histórico de los años sesenta, el tiempo del estreno de la pieza.

El uso de los multimedia permite visionar la obra sin sonido, el texto para ser leído, y el resultado de la conjunción de ambos textos -verbal y no verbal-, tal y como se representaron en escena. Podemos adentrarnos así en facetas insospechadas de análisis crítico.

En otro orden, el montaje de Esperando a Godot, dirigido por Sáinz de la Peña, en el que todos los personajes estaban encarnados por 
mujeres, la Niña mensajera de Godot, en su diálogo con Vladimiro y Estragón, cada sí que pronunciaba iba acompañado de un gesto negativo con la cabeza y, viceversa, cada $n o$, con un gesto afirmativo.

La Niña no pretendía que Vladimiro y Estragón entendieran lo contrario de lo que se estaba diciendo, sino que neutralizaba sus palabras para mantener la ambigüedad de su mensaje.

1.2. Ferrucio Rossi-Landi (1976: 53 y ss.) estableció una equiparación entre los artefactos materiales y orales creados por el hombre, cuya producción ha sido posible por una reciprocidad simbiótica. «Ningún artefacto material habría podido crearse sin la posibilidad de designarlo y comunicar su utilidad; y, recíprocamente, no podría (nadie) aprender a hablar sin distinguir y manipular objetos» (56). Actúa, por tanto, en la producción de ambos tipos de artefactos un factor de raíz antropogénica. Y surge entre ellos no una analogía, sino una homología que permite la identificación y manipulación de los mismos, simultánea o indistintamente, dentro de una o varias estructuras.

La homología estructural será especialmente interesante en el análisis de las adaptaciones, dentro de lo que Torop (1995: 40) llamó traducción extralingüística, y que se ocupa de la transmutación textual de un arte a otro. Nos ocuparemos aquí de la traslación específica de la obra narrativa al arte o medio fílmico, en el que los artefactos materiales tienen o pueden tener una representación icónica, kinésica, audio-acústica, o de cualquier otro tipo, en connivencia con los artefactos orales.

Quizá resultaría más comprensible la denominación de traducción intersemiótica dada por Jakobson (1971: 261) a la traslación de una obra a otro arte, traslación por la que una parte de los signos lingüísticos son traducidos a sistemas no verbales.

Pero las adaptaciones son, generalmente, algo más que la traslación de una semiótica a otra. Frecuentemente, en las adaptaciones cinematográficas de obras narrativas se manipula el contenido por incontables motivos: ideológicos, económicos, artísticos, morales, etc. Desaparecen o aparecen personajes, se suprimen pasiones, se resuelven conflictos que en la novela quedan abiertos, se cambian caracteres, se altera el cronotopo, se intercalan textos nuevos o se reconvierten los códigos que fijan los mensajes. Se trata, pues, de una recreación de la que, a veces, no queda ni la seña de identidad del título. 
Aunque en los comienzos del cine mudo se usaron los textos dramáticos como guiones de rodaje, las necesidades del medio provocaron el nacimiento de una filmoliteratura que, como el teatro, se convirtió en un género más, cuyos productos, con algunas excepciones, están destinados a la realización, no a la edición. Su destinatario no es el lector sino el espectador.

No quiere decir esto que no haya una producción enteramente original. La retórica fílmica adquirió autonomía prontamente e influyó en la producción literaria. La técnica conocida como el ojo de la cámara no sólo afectó a los escritores de la Generación Perdida americana, muchos de los cuales fueron contratados por grandes estudios cinematográficos como guionistas, sino que tuvo una influencia generalizada, rastreable en la literatura europea de entreguerras, y mucho mayor en los movimientos de postguerra. No se pueden negar ciertos vínculos entre la generación, o grupo, de los angry young men y el free cinema inglés, o entre el nouveau roman y la nouvelle vague francesa.

1.3. No están bien definidas las fronteras formales de los conceptos que nos aproximan a las transcodificaciones. Torop (1995: 43-44) estima que un texto no es sólo una representación lingüística. No se puede olvidar su dimensión visual, aunque sólo sea virtualmente. Su olvido puede provocar el envejecimiento de una posterior traducción. El traductor desconoce frecuentemente el sincretismo que opera en la creación, con respecto a los diversos lenguajes que maneja el autor. Sus opciones a la vista de los cronotopos que le afectan a él y a los personajes dejan cosas sin concretar y elementos implícitos que no son evidentes para el traductor. De manera que la textualización de las estructuras del mundo no se hace en la traducción desde los mismos parámetros.

Aun teniendo en cuenta lo dicho, debemos distinguir, por una parte, las traducciones o adaptaciones que solamente transcriben las partes del texto literario en códigos perceptibles por diversos canales, de lo que son propiamente adaptaciones que cambian partes y elementos importantes de la obra; lo que puede añadir o imponer sentidos nuevos. Y, por otra parte, distinguir las traslaciones que se codifican dentro de los mismos repertorios de signos. Es decir, manejando las mismas estructuras semióticas en el mismo arte. Más o menos, lo que el Diccionario de la Real Academia acepta como versión. 


\section{LAS ADAPTACIONES}

\subsection{La traslación de una obra de una semiótica a otra comporta, como principio, un proceso de creación}

El paso frecuente de una narración literaria al cine necesita reajustar los elementos significativos a las condiciones de la producción. La dispersión de acciones en una novela de protagonista colectivo, por ejemplo, puede ser considerada poco eficaz por el director del film, que impondrá su criterio al guionista de la adaptación, haciéndole reducir el número de personajes, seleccionando y concentrando acciones, etc. En la adaptación de Sábado por la noche, domingo por la mañana de Alan Sillitoe, dirigida por Karel Reisz, el personaje Freddy, hermano de Arthur Seaton, el protagonista, desaparece. Algunas de sus intervenciones que se consideraban necesarias para la configuración de otros caracteres, pasaron al primo Bert. Las tres o cuatro pendencias en las que se ve envuelto Arthur se reducen a una en el film: aquélla en la que le propinan una paliza los dos militares, uno de los cuales es hermano de Jack, el marido de Brenda, la amante de Arthur. Independientemente de la reducción, en la película no queda suficientemente justificada la agresión, mientras que en la novela, uno de los militares es el marido de una anterior amante de Arthur. Y esto ocurre a pesar de que Alan Sillitoe fue también autor del guión cinematográfico.

Por el contrario, es posible que situaciones o rasgos que en la novela apenas si ocupan espacio puedan desarrollarse en amplias secuencias. Casi al comienzo de la adaptación cinematográfica de La insoportable levedad del ser de Milan Kundera (1992: 10) hay toda una secuencia erótica que relata el primer encuentro íntimo de Tomás y Teresa. Esa secuencia desarrolla una única frase, una oración simple de la novela:

«Diez días más tarde vino a verle a Praga. Hicieron el amor ese mismo día. Por la noche le dio fiebre y se quedó toda una semana con gripe en la cama».

2.2. La duración de las sesiones de cine fue otro de los lastres que el guionista tuvo y tiene al proyectar su adaptación. Hubo que esperar al año treinta y nueve para romper la duración de hora y media que se 
estableció como promedio al adquirir gran desarrollo la industria cinematográfica y multiplicarse las salas de proyección. Con Lo que el viento se llevó queda sin efecto el metraje convencional establecido por la industria, al menos en el tratamiento de las superproducciones. Sin embargo, también la novela de Margaret Michel sufrió los efectos de la adaptación. Baste recordar que los hijos habidos de los dos primeros matrimonios de Escarlata O'Hara desaparecen.

Pero da la impresión de que las modificaciones del texto habían sido introducidas en función de la sensibilidad de un público mucho más amplio que el de los lectores.

Conseguir una definición ambiental puede ser primordial para algunos temas. La progresividad de la tensión que llega a hacerse palpable puede imponer a la adaptación un ritmo diferente al de la novela original. La importancia del ambiente en Muerte en venecia de Thomas Mann, hizo a Visconti variar el ritmo que la anécdota del amor imposible, núcleo narrativo del film, necesitaba.

Siempre se ha considerado el ritmo como algo inherente a la obra de arte que guarda una cierta linealidad o progresión cronológica en su realización y consumo. Incluso se ha encontrado un rastro rítmico en las obras plásticas que juegan con situaciones estático-dinámicas.

Susan K. Langer (1967: 107) atribuye al imperativo de la propia actividad vital la necesidad de controlar la selección y secuenciación de acontecimientos. El ritmo cardíaco o respiratorio, la alternancia sueño/vigilia, etc. inducen al ritmo en la configuración estética de la obra de arte.

Ya a principio de siglo, Méndez Bejarano (1908: 15 y ss.) iniciaba su libro, La ciencia del verso, con un estudio histórico del ritmo en el que incluye la controversia del carácter cuantitativo del ritmo poético, frente a pensadores y poetas como Krause o Lamartine, que estimaban la libertad rítmica como único fundamento de la poesía, de la que no se podía excluir el género novelesco. El anatema lanzado por Méndez Bejarano, aferrado a la identificación poesía/verso y ciñendo el ritmo a las reiteraciones métricas, nos lleva a la aceptación generalizada de las diferencias rítmicas entre prosa y verso. Este hecho plantea nuevos problemas al aceptar la teoría de Spencer de que los sentimientos buscan un ritmo. Y, sobre todo, al tomar en consideración la comunicación no verbal.

Núñez Ramos (1995) encuentra en el cine una relación muy directa con los tres géneros básicos literarios, o poéticos: con la poesía 
dramática, porque muestra los personajes en acción; con la narrativa, porque la voz de la novela queda homologada a la mirada; con la lírica, porque el propio acompañamiento de la banda sonora, y, sobre todo, por el ritmo que impone al conocimiento sensible que las otras dos relaciones proporcionan.

No hay una correspondencia estricta entre las unidades rítmicas de prosa y verso. Si bien es cierto que la sílaba es una unidad común a ambos ritmos, es la configuración de grupos fónicos recurrentes lo que marcará la diferencia. La reiteración del cómputo de sílabas ha de incidir en la distribución de acentos rítmicos, lo que dará un ritmo compacto, no alterable por la distribución de pausas y cadencias. Si tal alteración se produjera, el ritmo obtenido pertenecería a la prosa, aunque se trate del verso libre que desde el ultraísmo aparece en nuestro estro poético. Se trata aquí de un ritmo interno, de las combinaciones métricas, no de la reiteración de fonemas en la secuencia fonológica que conocemos como rima y aliteración, ni de la observación del plano del contenido.

Algunos teóricos como Adorno y Eisler (1981: 122-123) asimilan el ritmo cinematográfico al ritmo de la prosa, precisamente por el fluir constante del film y la heterogeneidad de los elementos recurrentes. Núñez Ramos les reprocha que tal clasificación es consecuencia de no haber tenido en cuenta las repeticiones y las simetrías de carácter musical que darían un ritmo poético.

Fuera de tal disputa, el cine, como soporte de la narrativa, tiene mucho que ver con la estructura dramática superficial; es decir, la estructura del desarrollo de la acción. La comparación de planos y secuencias está siempre en función de ella. En este sentido, tienen razón Adorno y Eisler. Lo que en la narración cinematográfica marca su ritmo es el modo de arranque, la gradación de la tensión para llegar a los climax y la efectividad de las escenas reflexivas (anticlimax) en combinación con las peripecias posibles. Romper este paradigma de la acción, sin una base teórica que lo justifique, es renunciar gratuitamente al ritmo cinematográfico, que sólo cambia en los géneros en los que la diégesis no cuenta. Se corresponde, pues, con la estructura de la acción que la crítica teatral decimonónica reconocía en l'oeuvre bien faite (la obra bien hecha). En este sentido poco puede aportar el ordenador, salvo el rastreo estadístico del texto escrito, que proporcione algún indicador rítmico, o la duración en el film de planos y secuencias. Pero conscientes siempre de que el ritmo es una apreciación global y subjetiva. 


\section{EL JUEGO DE LAS HOMOLOGÍAS}

Nuestra experiencia nos permite intuir lo que los hechos que protagonizamos o presenciamos directa o indirectamente corresponden a una concepción del mundo, estructurado bajo el imperio de la lógica, en la que los principios realistas - coordenadas espaciotemporales, contigüidad, principio de causalidad, etc.- nos abren paso a su comprensión. Tal estructuración colabora en la producción del sentido, dando fe de las homologías que se producen entre los sistemas significativos; es decir, las estructuras semióticas.

Sin embargo, los avances de las ciencias (Planck, Einstein, Oppenheimer) y nuevos planteamientos filosóficos (Husserl, Bergson) han dado al traste con esta estable concepción del mundo, que separa la realidad de la ficción, de lo maravilloso o de lo mágico, en donde el sueño, el subconsciente en general, hace su aportación.

3.1. Es conocida la vinculación que los escritores del nouveau roman tuvieron con la nouvelle vague del cine francés. Robbe-Grillet (1965: 169-174) planteó consideraciones nuevas, que afectaban a la estructura global de la obra, sobre la temporalidad y «la trampa de la anécdota». Rompía así la estructura cerrada de la narración realista.

Sobre el presente perpetuo o presente total que él intenta describir o imponer, confiesa que es más fácil mostrarlo en el cine, por la concurrencia de signos, y no linealidad, que juega en la fotografía.

Álvaro del Amo (1966), hablando de la dialéctica de la memoria de Marguerite Duras, apunta que para ella la tensión entre memoria y olvido marca la opción entre toma de conciencia y alienación. Así pasa con la Emmanuelle Riva de Hiroshima, mon amour, que construye su consciencia con la memoria y asunción del hecho histórico, aunque sea una falsa memoria extraída del museo. La memoria no tiene el valor de reconstruir cronológicamente unos acontecimientos, sino de darles existencia como fenómenos que se superponen. Proust estaba convencido de que nada es real hasta que no se ha recordado.

La función de la memoria como procedimiento para asumir unos acontecimientos trascendentes para su propio ser vuelve a abrirse en $E l$ amante de la China del Norte. Margarita Duras rescribió así El aman$t e$, que le había valido el premio Goncourt. Lo hizo cuando conoció la muerte del Chino, porque, según ella, faltaba el tiempo entre los amantes (Duras, 1992: 9). Parece que hubo una versión más, anterior a $E l$ 
amante, pero la adaptación cinematográfica se hizo bajo el título último de El amante de la China del Norte, por lo que es de suponer que se hizo sobre la redacción definitiva.

Los acontecimientos que narra tienen bastante de autobiográficos. La novela no está escrita, sin embargo, a manera de confesión o autobiografía. La de Duras utiliza los recursos estilísticos que dieron a la corriente el nombre de objetivismo. Incluso se menciona a la protagonista como «la que no se nombra» (11). Y poco después (13) se dice que «La voz que habla aquí, escrita, es la del libro».

El intento de objetivación a ultranza queda fijado con esta aclaración. Las descripciones, el hablar siempre en tercera persona de la Niña, la búsqueda permanente de un punto de vista externo, y la propuesta de un posible film sobre el tema, que va produciéndose a lo largo del relato, se ven alterados en la adaptación, que toma la forma de confesiones o memorias. La voz subjetiva, en primera persona, comienza a escucharse en off, mientras la imagen representa una mano que escribe.

Se trata de una cuestión formal que no distorsiona el relato, si bien se ha pasado a una focalización interior. Lo que sí hay que señalar es que en la creación del contexto se introducen palabras e ideas inexistentes en la novela. La voz es la de una mujer madura que habla en pasado: «Muy pronto, en mi vida, era ya demasiado tarde...».

La homologación de las voces (la del libro, la de la protagonista, la del autor-dios...) asegura la conducción por el itinerario narrativo y su elección responde a planteamientos teóricos. Pero, al participar de la estructuración global, los contextos pueden suplir la voz; no sólo porque las estructuras kinésica e icónica se hallen en una situación de recambio, supliendo la función significativa de la palabra, sino también porque la forma dialogada de la estructura linguiística crea los entornos necesarios para silenciar la voz del libro. Los multimedia permiten experimentalmente conmutar, en determinados puntos, las voces (la del libro y la del film) que estructuran la narración, y comprobar su incidencia en el componente semántico.

Se ha trivializado el recurso de dar un tratamiento anafórico al diálogo: el diálogo de la escena siguiente invade el último plano de la secuencia anterior, con una función premonitoria. Pero lo que no ha tomado todavía carta de naturaleza en la retórica habitual del cine, aunque esporádicamente se haya hecho, es la utilización del diálogo como contrapunto de las imágenes. La sugerencia de un nuevo 
contexto que las palabras dan, las sitúa en una relación estructural divergente, que puede señalar simultaneidad, o simplemente contraer una función metalinguíística. Esto es, la explotación de un hipertexto que abre nuevas posibilidades expresivas y que los multimedia permiten desglosar en sus diferentes planos.

La homología estructural amplía, pues, el juego de los sistemas de signos, aunque introduzca un factor de ambigüedad en la recepción.

3.2. Debemos abordar el problema de la intercalación en las adaptaciones de textos no fijados por el autor, que pasan a integrarse en la estructuración global.

En El amante de la China del Norte no se han suprimido personajes importantes en la adaptación, pero sí algunos aspectos de las relaciones entre ellos. Se suprime, por ejemplo, la relación (cuasi incestuosa) de la Niña y el hermano pequeño, cuya condición (probablemente es autista) no queda del todo explícita en el film.

Es posible que fuera una de las razones por las que la adaptación disgustó a Margarita Duras. No fue consultada, pese a su experiencia de guionista cinematográfica.

Al suprimir esa relación, cayó también la escena primera de la novela: una fiesta sui generis, organizada periódicamente para baldear la escuela de la madre. La escena está introducida, aparte de porque así ocurriera en la realidad, para poner de manifiesto el rencor de Pierre hacia Paulo (Paul en la película). Arroja a su hermano pequeño por una ventana del entresuelo al patio.

También se elide la secuencia siguiente en la que la Niña va a buscar a Paulo hasta la residencia del Administrador General.

El planteamiento de la situación queda sustituido por la reflexión de la voz en off, que sirve de introducción a la secuencia en la que se conocen los protagonistas. La voz de la mujer madura dice: «Diré más, tengo quince años y medio. El paso del transbordador por el Mekong...».

Queda claro que se mutila la personalidad compleja de la Niña. Por tanto, en la adaptación no se ha buscado homologar la voz del libro y la del film. La configuración del personaje va por derroteros distintos. Los «artefactos» que constituyen ambas voces tienen finalidades distintas. La del film, sentar las bases que definen un carácter, con conocimiento de causa, mientras que la del libro, relatar unos hechos que expliciten ese carácter. 
3.3. Esa utilización de una voz no fijada por el autor plantea el problema de la intertextualidad que propone Julia Kristeva (1981: 150), ya que no es un texto extranovelesco, sino una suplantación autoral, una ingerencia en el proceso de creación. Sería más propio hablar de transtextualidad (Genette, 1982), dando una mayor amplitud a la relación entre los textos de Marguerite Duras y de Jean-Jacque Annaud, aun cuando el texto de este último sea un assemblage de textos de la Duras.

Tras las escenas suprimidas del comienzo, sigue otra engarzada en la película de forma diferente de como se hace en la novela. Se trata de la escena en la que madre e hija se confiesan algunas circunstancias y afectos. En el film constituye un segmento cronológico dentro de la retrospección a la que somete la obra la voz de la «mujer madura». Y hablo de segmento cronológico porque la secuencia de la escena, en la que se pone de manifiesto la actitud tiránica de Pierre, antecede a la de la madre e hija. No está engarzada a manera de flash-back, en el relato de la madre, sino en la sucesión de los acontecimientos. Es decir, de forma lineal. El film intenta sobrecargar la actitud de Pierre en la escena. No llega cuando Paulo ha tomado ya el trozo más grande de thi$k h o$, como en el libro, sino que él había escogido ya, y no sólo le arrebata a Paulo el trozo más grande de su plato, sino que con un gesto despectivo y de dominio, devuelve a la fuente los trozos pequeños que había tomado con anterioridad. Esta escena asume la significación de todas aquéllas en las que se muestra la persecución a la que Pierre somete a su hermano.

Pese a estas formas diferente, en cuanto a engarce e intensidad de presentar la escena, sí que hay una cierta homologación entre ellas, puesto que la escena cumple las mismas funciones en la novela que transcodificada en el film.

3.4. Algunas secuencias de las adaptaciones presentan variaciones sobre personajes equivalentes de la obra literaria original. Este hecho no tiene por qué romper la homologación, aunque pueda dar matices distintos.

La primera insinuación que se cruzan los amantes en el Morris Léon Bollée la realizan mediante un juego de manos cuya significación está suficientemente codificada. Es posible que el ordenador pueda reconducir el movimiento de las manos que aparece en el film en el sentido descrito en el libro, aunque todavía no pueda hacerlo el ordenador personal. No importa que tengan ese deshumanizado 
movimiento cibernético que el cine y la televisión han codificado para los personajes de carácter robótico. En la novela, la iniciativa es de la Niña y demuestra su desenvoltura. Su insinuación es descarada. En cambio, Annaud optó por una forma más convencional. Es el Chino quien tiene una tímida iniciativa: un contacto lateral de las manos. Al ver que la Niña no retira la suya del asiento, la coge. Ella acaricia con su pulgar el índice de la de él. La comunicación entre ellos por canal táctil es suficientemente explícita, mientras que la estructura kinésico-icónica informa a los espectadores. La imagen asume aquí todos los valores expresivos. La duración de los planos con el enfoque alternante de manos y rostros informan de la intimidad de los sentimientos y de las decisiones que los personajes toman. La comparación de estos planos, que marcan la narración, posee el efecto cinematográfico. Como diría Lotman (1979: 83), contribuye a lograr un ritmo, y la homología estructural hace innecesaria la expresión linguística en cualquiera de sus formas. Es decir, la asociación de las estructuras kinésica e icónica funciona, en este contexto, en situación de recambio.

\section{CONCLUSIONES}

a) Los convencionalismos genéricos y los lenguajes específicos imponen diferenciales rítmicos apreciables entre las obras originales y sus adaptaciones a otros medios. Es una realidad que puede servir para determinar los shifters de las transcodificaciones y contrastar y valorar los resultados estéticos.

b) Con la adaptación se genera un proceso de recreación que no siempre es inocuo y respeta el sentido originario de la obra, independientemente de quien o quienes la llevan a cabo.

c) La homología estructural permite una adecuación del lenguaje al medio y una libertad estética a la mano rectora de la adaptación.

No obstante, hay que señalar que los segmentos significativos con los que se juega pueden desempeñar las funciones previstas en el texto original, pero pueden no responder a una traslación estricta a los sistemas sígnicos y su modo de codificación que intervienen en el nuevo medio. Su contraste inmediato podrá efectuarse en el proceso de multimedia, tal y como hemos previsto. 


\section{Referencias bibliográficas}

ADORNO, TH.W. y EISLER, H. (1981). El cine y la música. Madrid: Fundamentos. AMO, Álvaro del (1966). «Muriel, al regreso de Hiroshima». Nuestro cine 50, 23-29.

DURAS, Marguerite (1992). El amante de la China del Norte. Barcelona: R.B.A.

GenetTE, Gérard (1982). Palimpsest. París: Seuil. (Trad. esp. Madrid: Taurus). Greimas, A. J. y Courtès, J. (1990). Semiótica. Madrid: Gredos.

Grupo TÁBANo. (1971). «El juego de los dominantes». Tropos 1 (marzo). Madrid.

JAKOBSON, Roman (1971). «On Linguistic aspect of traslation». En Selected Writings. 2 Word and Language. La Haya-París: Mouton.

KrISTEVA, Julia (1981). Semiótica 1. Madrid: Fundamentos, 2 vols.

KUNDERA, Milan (1992). La insoportable levedad del ser. Barcelona: R.B.A.

LANGER, Susan K. (1967). Sentimiento y forma. México: UNAM.

LOTMAN, Iuri (1979). Estética y semiótica del cine. Barcelona: Gustavo Gili. Margallo, Juan. (1975). «De la crueldad al cachondeo». En Tábano. Un zumbido que no cesa, Equipo Pipirijaina. Madrid: Ayuso.

Méndez Bejarano, Mario (1908). La ciencia del verso. Madrid: Victoriano Suárez.

NúÑEZ RAMOs, Rafael (1995). «El ritmo en la literatura y el cine». Signa 4, 181-199.

Rossi-Landi, Ferrucio (1976). Semiótica y estética. Buenos Aires: Nueva Visión.

TOROP, Peeter (1995). «Semiótica de la traducción y traducción de la semiótica». Signa 4, 37-44. 